\title{
E. Albert Reece and Robert L. Barbieri: Obstetrics and Gynecology: The Essentials of Clinical Care
}

\section{Thieme Publishers, New York}

\author{
Dalal Asha
}

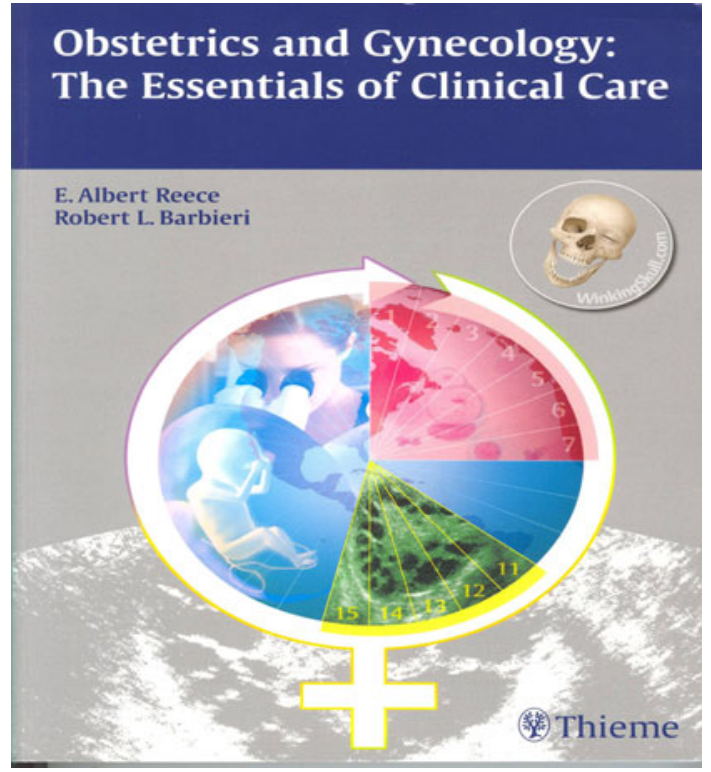

As mentioned on the reverse of the front cover, this book definitely has what you need to gain a solid foundation in the clinical essentials of obstetrics and gynecology.
A lot of information is compressed in the 500 odd pages in a very readable manner.

The chapters on Genetics and Genomic Applications in Obstetric and Gynecology Practice, Psychiatric issues during and after Pregnancy and the Biology of Cancer are few examples where the subject is explained in such a startlingly clear and simple fashion that it is easy for everyone to understand.

An attempt has been made to include the most common gynecological operative procedures with illustrations which is an added advantage.

Most topics are covered from the clinical aspect and that is what it should be read for or referred to.

This book includes an access code to register for Winking Skull.com PLUS by which one can access over 500 multiple choice questions organized chapter by chapter free of charge, which is an added advantage for students who would like to test themselves.
Dalal A. $(\bowtie)$, Obstetrician \& Gynecologist

Nair Hospital, Mumbai, India

e-mail: ashard@hotmail.com 